\title{
Predicting Tourists Decisions to Adopt Mobile Travel Booking
}

\author{
Yang Yang ${ }^{1}$, Zhuling Zhong ${ }^{1}$ and Mu Zhang ${ }^{2}$ \\ ${ }^{1}$ School of Management, Jinan University, Guangzhou, China \\ 2 Corresponding author Shenzhen Tourism College, Jinan University, Shenzhen, China \\ Jnu.yangy@163.com,Zsbox@163.com,Zhangmu@163.com
}

\begin{abstract}
This study aims to investigate the factors that predict tourist intention of using mobile travel booking with the technology acceptance model (TAM) as a base model. Variables such as perceived usefulness, perceived ease of use, perceived enjoyment, mobility and cost are used to examine the adoption intentions of tourists. The proposed model is empirically tested using data collected from a survey of tourists from Guangzhou and Shenzhen famous tourist attractions. The structural equation modeling technique is used to evaluate the causal model and confirmatory factor analysis is performed to examine the reliability and validity of the measurement model. The results show that all variables except perceived enjoyment significantly affect tourists' usage intention. Among them, the perceived usefulness has the most significant influence.
\end{abstract}

Keywords: Mobile travel booking, TAM, Mobility, User adoption, SEM

\section{Introduction}

With the rapid development of $3 \mathrm{G}$ networks, popularity of smart mobile and prosperity of apps, mobile phone has become the major method for netizens surfing on the Internet. According to the thirty-first Internet development situation statistics report of CNNIC (China Internet Network Information Center) [1], the scale of China's mobile phone users was growing rapidly and it had outnumbered PC netizens for the first time at the end of June 2012. Up to the end of December 2012, the number of China's mobile phone users has reached 420 million, an annual growth rate of $18.1 \%$, far exceeding the overall growth of Internet users; In addition, the proportion of Internet users in the use of mobile phones continues to improve, rising from $69.3 \%$ to $74.5 \%$. A huge user market of Mobile Internet is attracting the entry of various Internet companies and operators, which changes consumer behavior of mobile phone users. Mobile travel booking, as a new way of booking, refers to the consumer using mobile phone, computer and other portable mobile terminal equipment, through the GPRS, 3G, WiFi and other wireless network to book air tickets, hotels, resorts and other tourism product or service. What's more online payment or offline payment behavior has entered people's field of vision. Chinese netizens online travel booking behavior survey report [2] indicated that in June 2012, the quantity of netizens online travel booking was 42.58 million and only $13.1 \%$ of them had the experience of mobile travel booking. Whereas it's convenient, many users enjoy its quick and mobile characteristics. Since travel booking service and mobile Internet have the characteristics of natural fusion, as well as the increasing demand for tourism in recent years, mobile travel booking will usher a quick development opportunities. To have a head start in mobile travel booking, the enterprise should first recognize the factors that can influence the mobile travel booking intention and targeted formulate business strategy to improve the performance of mobile travel booking. 
In previous works of predicting human behavior decision, Markov decision processes (MDPs) is often used to solve many decision problems which are dynamic in nature and must be re-evaluated over time based on the state of some crucial underlying factors, such as machine state, company finances, etc. Planning domain definition language (PDDL) was first developed by Drew McDermott et. al., in 1998, which has become the de-facto standard language for representing classical planning tasks [3]. Antonio and Giuseppe proposed the concept of situation prediction that could detect dangerous situations and analyze abnormal behaviors by considering current user action and probability distribution of future situation [4].Among the numerous theory models which affect behavior adoption and usage, technology acceptance model is widely accepted as a framework to understand users' IT acceptance processes.

Therefore, this research integrates perceived enjoyment, mobility and cost into the TAM to investigate what affect the mobile travel booking acceptance by using structural equation model (SEM) to analyze the relationships among these factors. Results of this study are useful to mobile travel booking enterprises for formulating strategic suggestions to increase mobile travel booking services and promote customers' satisfaction in the future. This paper proceeds as follows: Section 2 introduces the literature review about technology acceptance model and mobile booking. Section 3 provides research model and hypotheses. Section 4 details the measures and data collection, and Section 5 presents the data analysis and hypotheses testing results. Section 6 discusses our research findings and implications for theory and practice. Finally, we suggest conclusion and potential topics for future research.

\section{Literature Review}

\subsection{Technology Acceptance Model (TAM)}

Technology Acceptance Model (TAM) was first proposed by American scholar Davis based on the theory of reasonable action (TRA), which mainly used to explain and predict how users come to accept and use a technology [3]. According to TRA, a person's particular behavior is determined by behavior intention, and behavior intention is determined by attitude and subject norm. The original TAM consists of four constructs including two determining factors to accept information technologies, namely perceived usefulness (PU) and perceived ease of use (PEOU), attitude toward using (ATU) and behavioral Intention to use (BI). PU is the degree to which one believes that using the technology will enhance his/her performance and PEOU is the degree to which one believes that using the technology will be free of effort. PEOU is assumed to have a positive direct effect on PU while PU has a positive direct effect on BI. Many studies have validated TAM as a robust and parsimonious framework for understanding the user's adoption of technology in various contexts. Huang et. al. provided a research framework to explore user acceptance of 3D virtual worlds in travel and tourism marketing by extending the technology acceptance model [4]. Lee et. al., investigated the effect of Facebook users' arousal and valence on intention to go to the festival by applying an extension of the technology acceptance model [5]. Chen and Chen investigated factors affecting travelers' usage intentions of in-vehicle GPS products and examined the moderating effect of personal innovativeness on the relationship between attitude and behavior intention based on technology acceptance model and unique features of GPS devices [6]. Technology acceptance model has also been revised to incorporate additional variables with specific contexts. Taylor and Todd's research found that attitude had no significant influence on BI and PEOU affect BI directly, so they suggested TAM should to be given additional variables but it omitted ATU due to its weak effect on BI [7]. This conclusion had been proved by 
Venkatesh \& Davis [8]. Therefore, the constructs of perceived usefulness, perceived ease of use and behavior intention are included in this study for a better understanding of mobile travel booking.

\subsection{Mobile Booking}

The first decade of the 21st century has been considered as the decade of mobile computing. With the development of mobile commerce, scholars began to pay attention to mobile booking. Wang and Wang investigated the adoption of mobile hotel reservation services from the perceived value perspective, the results indicated that perceived value was a predictor in explaining the customer's adoption of mobile hotel reservation and perceived fee on perceived value were significant [9]. Kwon et. al., employed the TAM to examine the reasons why customers downloaded mobile applications offered by companies in the hospitality industry and they found that consumers who enjoyed using smartphones and who were confident in themselves were more likely to download the mobile applications [10]. Mallat et. al., developed and tested a mobile adoption model that addressed the features of mobile technologies and services. They found that it was significant in predicting mobile ticketing adoption [11]. Cheng and Huang investigated high speed rail passengers' acceptance of mobile ticketing services and results indicated that a combination of the mental accounting theory and TAM was appropriate for explaining passengers' mobile ticketing service adoption [12]. A detailed literature review indicated that there were quite a few studies on the adoption of mobile travel booking from the travel standpoint. Thus, this paper attempted to investigate what affected the mobile travel booking acceptance based on technology acceptance model.

\section{Research Model and Hypotheses}

\subsection{Research Model}

According to the literature review and related concept about the TAM and its application on mobile booking, the authors designed a model indicating the adoption of mobile travel booking. In this model, perceived usefulness, perceived ease of use and behavior intention were included. Three other external variables, perceived enjoyment, mobility and cost, were also integrated into the model, as depicted in Figure 1. We will test the strength of the hypothesized relationships embedded in theoretical model and the robustness of the model in predicting tourists' intention to adopt mobile travel booking.

\subsection{The Hypotheses Design}

3.2.1. Hypotheses Relative to TAM: As TAM are used as the base model, we need to test the following TAM hypotheses in the context of mobile travel booking, therefore, based on the theoretical model developed in Section 2, we formulated the following research hypotheses.

H1. Perceived ease of use has a positive effect on perceived usefulness.

H2. Perceived usefulness has a positive effect on behavior intention to use.

H3. Perceived ease of use has a positive effect on behavior intention to use. 


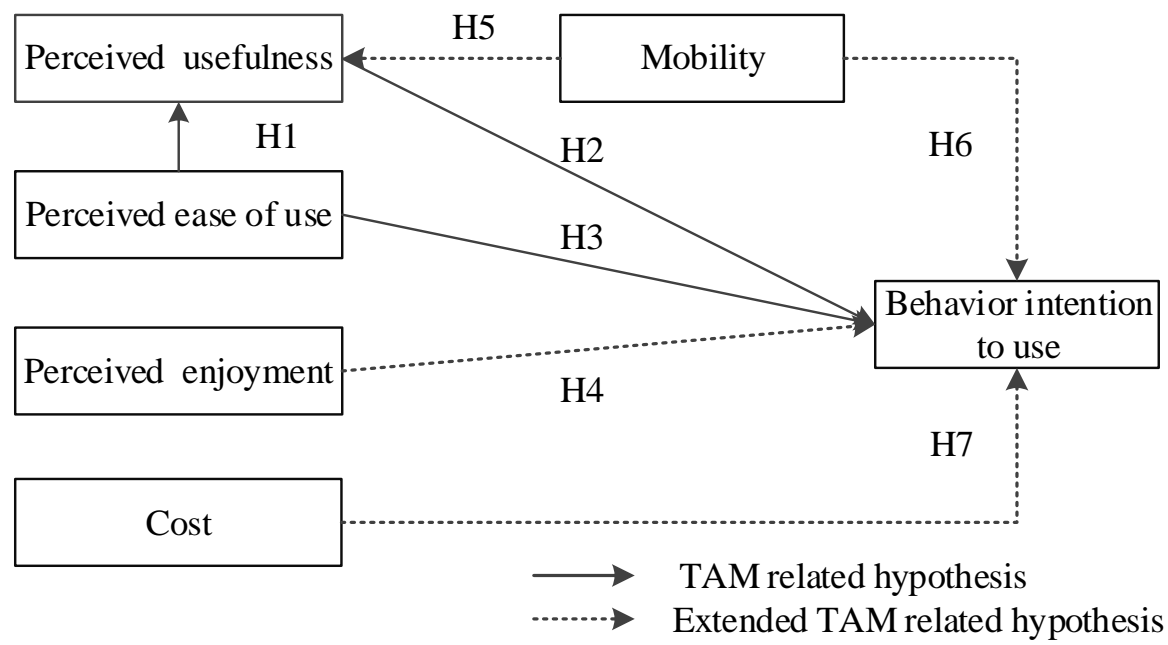

Figure 1. Proposed Research Model for Mobile Travel Booking Acceptance

3.2.2. Hypotheses of Perceived Enjoyment: Perceived enjoyment plays a significant role in one's acceptance of new technology. Davis et. al., [13] introduced the concept of perceived enjoyment to extend the original TAM. Perceived enjoyment is defined as "the extent to which the activity of using the technology is perceived to be enjoyable in its own right, apart from any performance consequences that may be anticipated", which influence the BI directly. Heijden [14] also proved that perceived enjoyment positively influences the intention to use a websites. Research in the field of mobile commerce, Ha et. al., [15] analyzed the factors that influence potential users' adoption of MBWA games using an extension of TAM, the results revealed that the effect of perceived enjoyment was very important. Chong [16] had confirmed that perceived enjoyment significantly influence the intention to use mobile commerce. In the tourism process, people may hold the joyful mood to touch the mobile travel booking. If people can experience the enjoyment from the use of mobile travel booking, it may enhance people's intention to use. Hence, the following hypotheses are proposed.

H4. Perceived enjoyment has a positive effect on behavior intention to use.

3.2.3. Hypotheses of Mobility: Mobile phone and other mobile terminals have become an essential tool for information exchange in the travel process, and they can link with travel seamlessly. According to Ngai and Gunasekaran [17], the two major functions of smartphones are mobility and broad reach. This allows consumers to conduct business and be reached via smartphones at anytime and anywhere. Mallat et. al., [11] examined consumer adoption of mobile ticketing services and suggested that use context fully mediated the effect of mobility on use intention. Mobility in their study was used to express the benefits of time and place, service access and use. And what is the difference between mobility and usefulness is perceived usefulness capturing the benefits of technology in general, whereas mobility focuses on the advantages of mobile technology. Thus in our study, mobile travel booking is different from mobile business activities in general, such as mobile payment and mobile office which not only stress that people can book, pay and office in a mobile context, but also match the surrounding tourism production or service based on location, namely LBS. It will change with the change of location and time. Schierz et. al., [18] developed a conceptual model focusing on factors determining consumers' acceptance of mobile payment services, the results showed that mobility was an important factor for the user to accept mobile 
payment services and there was a positive correlation between the mobility and perceived usefulness. Hence, the following hypotheses are proposed.

H5. Mobility has a positive effect on perceived usefulness.

H6. Mobility has a positive effect on behavior intention to use.

3.2.4. Hypotheses of Cost: Cost is one of the reasons that could slow down the development of mobile travel booking. Mathieson et. al., stated that the cost factor was one of the main determinants of $3 \mathrm{G}$ services adoption [19]. Kleijnen et. al. suggested that perceived service cost had a significant effect on the intention to use wireless financial services [20]. According to the Luarn and Lin, cost may consist of initial purchase price (e.g., handset fee), ongoing usage cost (subscription fee, service fee and communication fee), maintenance cost and upgrade cost [21]. In conjunction with the mobile travel booking own characteristics, this paper considers the cost of mobile travel booking mainly including: the purchase of mobile equipment (e.g., smart phone and IPAD), 3G or GPRS package subscription fees and produced in the process of booking traffic fees. Wei et. al., stressed that cost was one of the reasons to prevent consumers in Malaysia accepting M-Commerce [22]. Chong et. al., in their comparative study between Malaysian and Chinese mobile commerce found that cost had significant negative effect on behavior intention [23]. Although with the improvement of people's economic level, mobile phone and mobile phone Internet is very popular in our daily life, but taking the large number young users of into account, especially university students and fresh person out of the university with limited consumption capacity it is necessary to examine if cost affects the young group. Hence, the following hypotheses are proposed.

H7. Cost has a negative effect on behavior intention to use.

\section{Research Design}

\subsection{Measures}

A self-administered questionnaire was designed to collect data for this study. Based on the literature review and specific features of research setting, the questionnaire was divided into two sections. The first section of the questionnaire asked about the respondents' information with six items, namely gender, age, education, duration of usage, booking product, usage experience. The second section included 21 questions measuring the respondents' perceptions about usefulness, ease of use, enjoyment, mobility, cost and their behavioral intentions. All items were measured with seven-point Likert scales ranging from 'strongly disagree $(=1)$ ' to 'strongly agree $(=7)$ '. Items for perceived usefulness and perceived ease of use were adapted from Davis' [3] TAM model. Perceived enjoyment was measured with three items adapted from Heijden [14]. Mobility was measured with three items adapted from Schierz et. al., [18]. The scale of cost was drawn from Chong et. al., [23]. The constructs of behavior intention were adapted from Taylor and Todd [24]. After the draft was designed, two tourism management scholars and one information systems scholar reviewed the instrument. As a pretest, a focus group of ten people (some of them had previous mobile travel booking experience, while others did not) also reviewed the instrument and provided feedback about the length of the instrument, content, question ambiguity and clarity of the questions.

\subsection{Data Collection}

The population of this study was tourists who have had experience of booking tourism product or service and who use smart mobile phones. According to the Guangdong Statistical 
Yearbook 2012 [25], Guangzhou ranked first with receiving 45.9485 million person-times of overnight tourists, Shenzhen with 37.3253 million person-times followed. Therefore, this study chose tourists from Guangzhou and Shenzhen, two famous tourist attractions, as the sample object, with distributing 500 pieces of paper questionnaires. The survey was conducted from November through December 2012. Excluding missing and invalid answers included questions answered wrongly, or left blank, 288 valid responses were collected. The valid response rate was $57.6 \%$.

\section{Analysis and Results}

\subsection{Sample Characteristics}

The demographic profile of the respondents was presented in Table 1, It showed that 159 respondents are males $(55.21 \%)$ and 129 are female (44.79\%). About 65\% of the participants were between 18 and 30 years old. The education levels of respondents were $21.87 \%$ senior high school, $60.42 \%$ college and $17.71 \%$ graduate. In terms of duration of usage, approximately $37.85 \%$ of the respondents did not have the experience of mobile travel booking but most of them have used it for no more than one year. Average usage time in Mobile travel booking per year was 1 3 times (58.66\%). Hotel was the most popular booking products $(91.18 \%)$, the other products were air ticket and scenic spot ticket.

Table 1. Sample Demographics

\begin{tabular}{cccc}
\hline Measure & Item & Frequency & Percent (\%) \\
\hline Gender & Male & 159 & 55.21 \\
& Female & 129 & 44.79 \\
Age & $18 \sim 24$ & 81 & 28.12 \\
& $25 \sim 30$ & 105 & 36.46 \\
Education & $31 \sim 40$ & 59 & 20.49 \\
& $>40$ & 43 & 14.93 \\
& Senior high school & 63 & 21.87 \\
& College/University & 174 & 60.42 \\
Duration of usage & Graduate (or & 51 & 17.71 \\
& above) & 109 & 37.85 \\
& None & 79 & 27.43 \\
& $<6$ months & 67 & 23.26 \\
Average usage time in booking per year & $6 \sim 12$ months & 33 & 11.46 \\
& 1 year (or above) & 105 & 58.66 \\
& $1 \sim 3$ & 54 & 30.17 \\
& $4 \sim 6$ & 20 & 11.17 \\
Booking products & $>6$ & 54 & 30.17 \\
& Air ticket & 103 & 57.54 \\
& Hotel & 22 & 12.29 \\
\hline
\end{tabular}




\subsection{Measurement Model}

First, we examined the measurement model to measure reliability and convergent validity. The composite reliability (CR) was estimated to evaluate the internal consistency of the measurement model. Convergent validity was assessed based on the criteria that indicator's estimated coefficient was significant on its posited underlying construct factor. There criteria suggested by Fornell and Larcker [26] were used:

(1) All indicator factor loading $(\lambda)$ should be significant and exceed 0.5 .

(2) Construct reliabilities should exceed 0.8.

(3) Average variance extracted (AVE) by each construct should exceed the variance due to measurement error for the construct (e.g. AVE should exceed 0.5)

As shown in Table 2, Cronbach's a for all variables are well above 0.7 which indicate that each construct exhibited strong internal reliability. The result also shows that all factor loadings are above 0.5 for all items, which indicates convergent validity for all latent variables. Composite reliabilities of constructs range from 0.801 to 0.917. While AVE, ranging from0.551 to 0.787, was greater than the variance due to measurement error. Therefore, all three conditions for convergent validity were met.

Table 2. Confirmatory Factor Analysis Results for Measurement Model

\begin{tabular}{ccccccc}
\hline Constructs & Item & $\begin{array}{c}\text { Factor } \\
\text { loading }\end{array}$ & t-value & $\begin{array}{c}\text { Cronbach's } \\
\text { a }\end{array}$ & CR & AVE \\
\hline \multirow{2}{*}{ Perceived } & PU1 & 0.85 & 10.66 & 0.84 & 0.872 & 0.631 \\
Usefulness & PU2 & 0.79 & 8.24 & & & \\
& PU3 & 0.82 & 9.46 & & & \\
Perceived Ease & PEOU1 & 0.71 & 7.47 & & & \\
of Use & PEOU2 & 0.81 & 7.62 & 0.75 & 0.832 & 0.632 \\
& PEOU3 & 0.95 & 3.28 & & & \\
Perceived & PE1 & 0.70 & 6.06 & & & \\
Enjoyment & PE2 & 0.86 & 6.15 & 0.77 & 0.801 & 0.551 \\
& PE3 & 0.65 & 6.61 & & & \\
Mobility & M1 & 0.90 & 11.05 & 0.86 & 0.884 & 0.718 \\
& M2 & 0.81 & 8.76 & & & \\
& M3 & 0.83 & 9.83 & & & \\
& C1 & 0.86 & 8.11 & 0.84 & 0.916 & 0.690 \\
& C2 & 0.78 & 6.70 & & & \\
Cost & C3 & 1.03 & 9.03 & & & \\
& C4 & 0.69 & 6.71 & & & \\
Bntention & C5 & 0.75 & 9.03 & & & \\
& BI1 & 0.89 & 15.73 & 0.92 & 0.917 & 0.787 \\
& BI3 & 0.91 & 15.78 & & & \\
\hline
\end{tabular}




\subsection{Structural Model}

Next, this study tested the causal hypotheses for research model by using structural equation modeling (SEM). We examined the model in terms of model goodness of fit and hypothesized causal links. In this study seven common measures of model fit were chosen. These include chi-square/degrees-of-freedom $\left(\chi^{2} / \mathrm{df}\right)$, goodness of fit index (GFI), root mean square error of approximation (RMSEA), root mean square residual (RMR), normed fit index (NFI), non-normed fit index (NNFI) and comparative fit index (CFI). The recommended value for these fit indices are suggested by Hair et. al., [27] and our results are shown in Table 3, which indicated that our model fit was acceptable.

Table 3. Chi-square Results and Goodness of Fit Indices for Structural Model

\begin{tabular}{ccc}
\hline Fit indices & Recommended value & Result \\
\hline$\chi^{2} / \mathrm{df}$ & $<3$ & 2.32 \\
GFI (goodness of fit index) & $>0.9$ & 0.90 \\
RMSEA (root mean square error of approximation) & $<0.08$ & 0.07 \\
RMR (root mean square residual) & $<0.08$ & 0.06 \\
NFI (normed fit index) & $>0.9$ & 0.92 \\
NNFI (non-normed fit index) & $>0.9$ & 0.93 \\
CFI (comparative fit index) & $>0.9$ & 0.91 \\
\hline
\end{tabular}

Given the acceptable fit of the model, the estimated path coefficients of the structural model were then studied to evaluate the hypotheses. PEOU and mobility had a direct positive effect on behavior intention with path coefficient of 0.66 and 0.12 , which providing support for hypothesis $\mathrm{H} 1$ and $\mathrm{H} 5$. PU, PEOU and mobility had a direct positive relationship to behavior intention with path coefficients of $0.71,0.35$ and 0.42 . This provided support for hypotheses $\mathrm{H} 2, \mathrm{H} 3$ and $\mathrm{H} 6$. A surprising result was that the direct path between perceived enjoyment and behavior intention was insignificant, and thus hypothesis $\mathrm{H} 4$ was rejected. Finally, cost had a negative effect on using intention with a 0.28 path coefficient providing support for hypothesis H7 (see Figure 2).

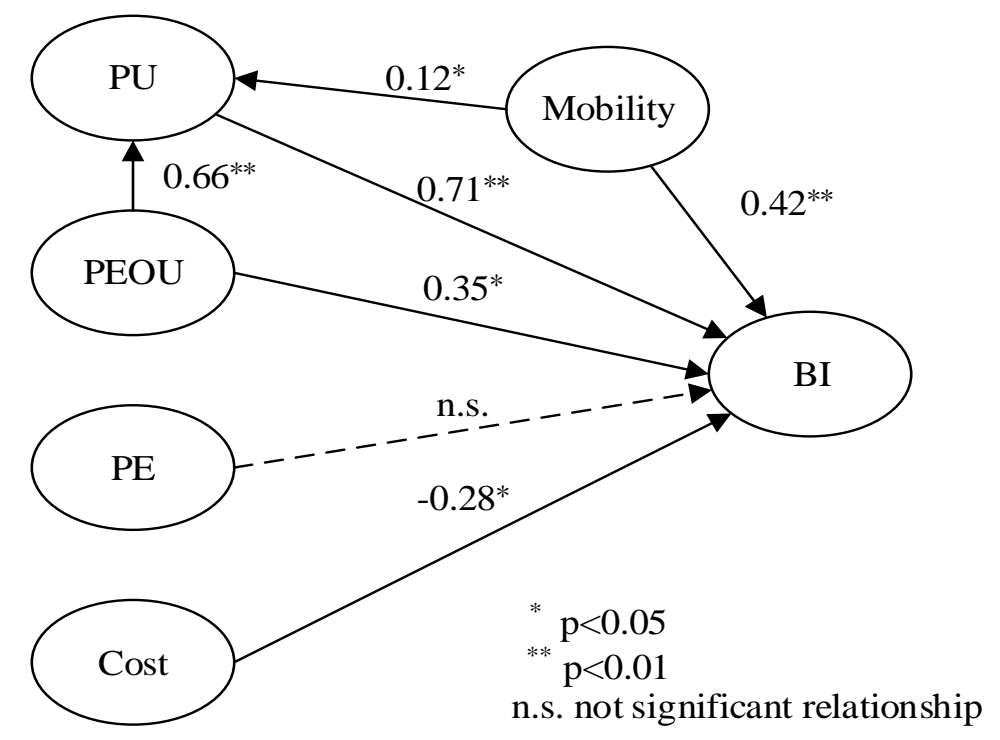

Figure 2. Results of Structural Modeling Analysis 


\section{Discussion and Implications}

This study contributes to the theoretical development predicting tourist behavior intention on mobile travel booking. The results of the study provide practical implications for marketing managers and practitioners who targeted formulate business strategy to improve the performance of mobile travel booking.

The results show that perceived ease of use has a positive effect on perceived usefulness while perceived usefulness has a significant effect on behavior intention, which is consistent with the original TAM model. Another result from this study is that perceived ease of use has a positive effect on behavior intention. This is supported by Venkatesh\& Davis at 2000 [8]. This implies that the more belief tourist have in the use of mobile travel booking, the more likely the tourist will view the mobile travel booking as useful. Therefore, these mobile travel booking providers should focus on designing both useful and easy-to-use mobile travel booking. They should be made more effective and efficient by allowing tourist to easily booking tourism product or services.

As presented in our findings, the most puzzling and surprising result is that perceived enjoyment does not significantly affect the behavior intention. This is in contrasts to the work of Heijden [14], who pointed out that perceived enjoyment positively influences the behavior intention. The reasons for this finding are not clear. Compared with mobile travel booking, mobile video or mobile games may be more attractive, more fun when people are bored to line up waiting to enter the scenic area. But it doesn't mean that we can ignore the perceived enjoyment of mobile travel booking. The developer can attempt to design the mobile travel booking more interesting like mobile games.

Our results suggest that mobility has a positive effect on perceived usefulness and behavior intention. This is in line with the previous findings of Schierz et. al., [18], which indicates mobility significant affect perceived usefulness and behavior intention. Therefore, mobile travel booking managers should be aware of the importance of mobility which is distinguished from online travel booking. The function of LBS (Location Based Service) that people can book different tourism products or service based on different locations must be added to the mobile travel booking.

Furthermore, we find that cost has a negative effect on behavior intention to use. This is in accord with the findings of Mathieson et. al., [19], Wei et. al., [22] and Chong et. al., [23]. They indicated that cost had significant negative effect on behavior intention. This finding implies that mobile telecommunication operators and service providers should take cost in account if they want to distinguish themselves in a highly competitive market. To reduce the cost, service providers can increase consumer's adoption intention by reducing the tariffs of value-added service. If the service tariff cannot be reduced, service providers should develop more valuable and special services.

\section{Conclusion and Future Study}

This paper aims to develop technology acceptance model to predict and explain user behavior intention to adopting mobile travel booking. We verified the effect of perceived usefulness, perceived ease of use, mobility and cost on the behavior intention of mobile travel booking. The results show that the proposed model has a good explanatory power and confirms its robustness in predicting user adoption on mobile travel booking.

This study also has several limitations. Firstly, the sample object of this study is a group of tourists from Guangzhou and Shenzhen, the limited research results cannot be used to generalize all tourists. Future studies can enlarge the sampled user group and compare the differences in behavior intention between different user groups. Secondly, the research design 
in this study is basically cross-sectional, that is, the survey is performed at a specific time point. Future studies need to evaluate the validity of the research model in a long-range framework. Finally, the mobile travel booking in China is still under development. Sampling all the practical user of mobile travel booking is not feasible. So the future studies can make an in-depth investigation when users have a higher level of involvement in mobile travel booking to acquire more objective arguments.

\section{Acknowledgements}

This research work is supported by the Key Project of the 11th Five-Year Planning of National Educational Science of Ministry of Education under Grant Nos. DIA100305, and the Jinan University's Scientific Research Creativeness Cultivation Project for Outstanding Undergraduates Recommended for Postgraduate Study under Grant Nos. 50503629.

\section{References}

[1] China Internet Network Information Center, "The Thirty-First Internet Development Situation Statistics Report", Available from CNNIC website: http://www.cnnic.net.cn/hlwfzyj/hlwxzbg/hlwtjbg/201301/ t20130115_38508.htm, (2012).

[2] China Internet Network Information Center, "2012 Chinese Netizens Online Travel Booking Behavior Survey Report", Available from CNNIC website: http://www.cnnic.net.cn/hlwfzyj/hlwxzbg/lxgb/201212/ t20121228_38447.htm, (2012).

[3] D. McDermott, "The 1998 AI Planning Systems Competition”, AI Magazine, vol. 21, no. 2, (2000), pp. 3555.

[4] A. Coronato and G. De Pietro, "Situation Awareness in Applications of Ambient Assisted Living for Cognitive Impaired People", Mobile Networks and Applications, vol. 18, no. 3, (2013), pp. 444-453.

[5] F. D. Davis, "Perceived Usefulness, Perceived Ease of Use and User Acceptance of Information Technology", MIS Quarterly, vol. 13, no. 4, (1989), pp. 319-340.

[6] Y. C. Huang, S. J. Backman, K. F. Backman and D. Moore, "Exploring User Acceptance of 3D Virtual Worlds in Travel and Tourism Marketing", Tourism Management, vol. 36, (2013), pp. 490-501.

[7] W. Lee, L. Xiong and C. Hu. "The effect of Facebook Users' Arousal and Valence on Intention to go to the Festival: Applying an Extension of the Technology Acceptance Model", International Journal of Hospitality Management, vol. 31, no. 3, (2012), pp. 819-827.

[8] C. F. Chen and P. C. Chen. "Applying the TAM to Travelers' Usage Intentions of GPS Devices", Expert Systems with Applications, vol. 38, no. 5, (2011), pp. 6217-6221.

[9] S. Taylor and P. Todd, "Assessing IT usage: the Role of Prior Experience", MIS Quarterly, vol. 19, no. 4, (1995), pp. 561-570.

[10] V. Venkatesh and F. D. Davis, "A Theoretical Extension of the Technology Acceptance Model: Four Longitudinal Field Studies”, Management Science, vol. 46, no. 2, (2000), pp. 186-204.

[11] H. Y. Wang and S. H. Wang, "Predicting Mobile Hotel Reservation Adoption: Insight from a Perceived Value Standpoint", International Journal of Hospitality Management, vol. 29, no. 4, (2010), pp. 598-608.

[12] J. M. Kwon, J. Bae and S. C. Blum, "Mobile Applications in the Hospitality Industry", Journal of Hospitality and Tourism Technology, vol. 4, no. 1, (2013), pp. 81-92.

[13] N. Mallat, M. Rossi, V. K. Tuunainen and A. Oorni, "The Impact of Use Context on Mobile Services Acceptance: The Case of Mobile Ticketing”, Information \& Management, vol. 46, no. 3, (2009), pp. 190-195.

[14] Y. H. Cheng and T. Y. Huang, "High Speed Rail Passengers' Mobile Ticketing Adoption", Transportation Research Part C, vol. 30, (2013), pp. 143-160.

[15] F. D. Davis, R. P. Bagozzi and P. R. Warshaw, "Extrinsic and Intrinsic Motivation to Use Computers in the Workplace", Journal of Applied Social Psychology, vol. 22, no. 14, (1992), pp. 1111-1132.

[16] H. V. D. Heijden, "Factors Influencing the Usage of Websites: the Case of a Generic Portal in the Netherlands", Information and Management, vol. 40, no. 6, (2003), pp. 541-549.

[17] I. Ha, Y. Yoon and M. Choi. "Determinants of Adoption of Mobile Games under Mobile Broadband Wireless Access Environment", Information \& Management, vol. 44, no. 3, (2007), pp. 276-286.

[18] A. Y. L. Chong, "A Two-Staged SEM-Neural Network Approach for Understanding and Predicting the Determinants of M-Commerce Adoption”, Expert Systems with Applications, vol. 40, no. 4, (2013), pp. 1240-1247.

[19] W. T. E. Ngai and A. Gunasekaran, "A Review for Mobile Commerce Research and Applications", Decision Support Systems, vol. 43, no. 1, (2007), pp. 3-15. 
[20] P. G. Schierz, O. Schilke and B. W. Wirtz, "Understanding Consumer Acceptance of Mobile Payment Services: An Empirical Analysis”, Electronic Commerce Research and Applications, vol. 9, no. 3, (2010), pp. 209-216.

[21] M. Pagani, "Determinants of Adoption of Third Generation Mobile Multimedia Services", Journal of Interactive Marketing, vol. 18, no. 3, (2004), pp. 47-59.

[22] M. Kleignen, M. Wetzels and K. de Ruyter. "Consumer Acceptance of Wireless Finance", Journal of Financial Services Marketing, vol. 8, no. 3, (2004), pp. 206-217.

[23] P. Luarn and H. H. Lin, "Toward an Understanding of the Behavioral Intention to Use Mobile Banking", Computer in Human Behavior", vol. 21, no. 6, (2005), pp. 873-891.

[24] T. T. Wei, G. Marthandan, A. Y. L. Chong, K. B. Ooi and S. Arumugam, "What Drives Malaysian MCommerce Adoption? An Empirical Analysis", Industrial Management \& Data Systems, vol. 109, no. 3, (2009), pp. 370-388.

[25] A. Y. L. Chong, F. T.S. Chan and K. B. Ooi. "Predicting Consumer Decisions to Adopt Mobile Commerce: Cross Country Empirical Examination between China and Malaysia”, Decision Support Systems, vol. 53, no. 1, (2012), pp. 34-43.

[26] S. Taylor and P. A. Todd, "Understanding Information Technology Usage: a Test of Competing Models", Information System Research, vol. 6, no. 2, (1995), pp. 144-176.

[27] Guangdong Province Bureau of Statistics. "The Guangdong Statistical Yearbook 2012", Available from http://www.gdstats.gov.cn/tjnj/2012/table/17/17-05.htm, (2012).

[28] J. F. Hair, R. E. Anderson, R. L. Tatham and W. C. Black, "Multivariate Data Analysis, Upper Saddle River, NJ: Prentice-Hall, (1998).

[29] C. Fornell and D. Larcker, "Evaluating Structural Equation Models with Unobservable Variables and Measurement Error", Journal of Marketing Research, vol. 18, no. 1, (1981), pp. 39-50.

\section{Authors}

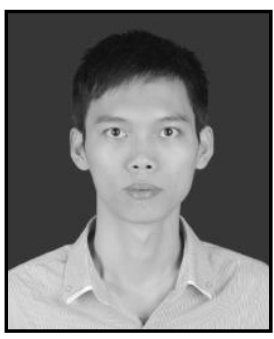

Yang Yang received his BS degree from Department of Electronic Business of Jinan University, Guangzhou, in 2012. Now, he is working his MS. Degree at the same University. His research interests include ecommerce in tourism and tourism management information system.

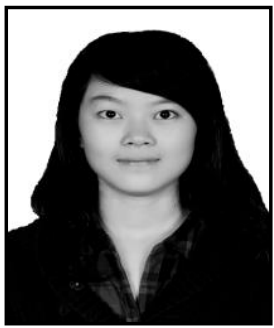

Zhuling Zhong received her BS degree from Department of Tourism of Jinan University, Guangzhou, in 2013. Now, she is working her MS. Degree at the same University. Her research includes ecommerce in tourism and tourism attractions design and plan.

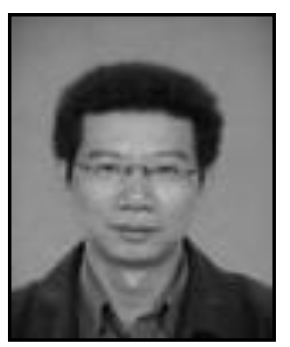

Mu Zhang was born in Changsha, China in 1964. He received the B.S, M.S, and Ph.D. degree in Geography from Guangxi Teachers College, Nanjing Normal University, Fujian Normal University, China, in 1985, 1997 and 2002 respectively. He was a visiting professor from 2013 to 2014 at Temple University. Since 2004, he has worked in Shenzhen Tourism College at Jinan University, where he is a professor and director of the GIS \& Tourism Information Technology Laboratory. His research interests are in ecommerce in tourism, tourism management information system and tourism attractions design and plan. 
International Journal of $u-$ and e- Service, Science and Technology Vol.6, No.6 (2013) 